\title{
Revista Papeles De Son Armadans: UMA PONTE ENTRE OS ESCRITORES DA PENÍNSULA E DO EXÍLIO
}

\author{
Solange Munhoz
}

Após o fim da Guerra Civil Espanhola (1936-1939), Franco assumiu o poder e consolidou um governo ditatorial (1939-1975) que durou até a sua morte. Tais acontecimentos políticos implicaram o exílio de um contingente numeroso de intelectuais e artistas que, em diferentes graus, passaram a ter dificuldades para publicar na Espanha, dado o rigor da censura estabelecida.

Apesar da atmosfera sufocante, no final dos anos 1950, circulavam no país as revistas Ínsula, ${ }^{1}$ Índice e Papeles de Son Armadans, reconhecidas como publicações que contribuíram para oxigenar a esfera cultural do período por, com maior ou menor frequência, abrirem espaço para os escritores exilados e pela qualidade dos textos e dos autores publicados. Max Aub (1971, pp. 9-10), escritor exilado e um dos mais perseguidos pela censura, explica sua decisão de publicar em Papeles e lista os problemas que encontrava ao submeter material às outras revistas por meio das seguintes palavras:

Yo quería (quiero) publicar en España. Lo malo, en 1950, era saber dónde. Ínsula, bien (y sigo). ¿Índice? De mi colaboración en esa revista tendría algo

\footnotetext{
1 Ao caracterizar Ínsula (de 1946), Jordi Gracia (2006, p. 284) afirma que era exemplo precioso pela capacidade de manter vínculos com a vida cultural anterior à guerra, com os exilados e, ao mesmo tempo, estar atenta às novas estéticas.
} 
que decir, pero su director no quiere y menos poner los puntos sobre las íes, y soy bastante mirado en eso de la ortografía y preferí darme por enterado [...]. No soy sectario; nunca envié página que no pudiera publicarse -o a lo sumo con una supresión insignificante si el burócrata se levantaba de peor humor el martes que el lunes [...].

Siento no poder hacerlo en revistas de gran circulación, pero comprendo que no íbamos a estar de acuerdo en los temas a tratar. A veces he dicho algunas verdades, lo que me lleva a suponer que colaboré en Papeles porque nunca quise dar mi brazo a torcer, y lo cierto es que no lo intentaron siquiera. De ahí mi feroz agradecimiento. ${ }^{2}$

Por outro lado, Ana Casas revela a postura diferente adotada pelas três revistas quanto à incorporação dos autores do exílio, explicando que Índice teria apresentado preocupação mais política e sido menos expressiva na veiculação de textos artísticos ou críticos. Sobre as outras duas, a pesquisadora estabelece a seguinte comparação:

Papeles de Son Armadans cumple una misión, respecto al exilio, parecida a la de Ínsula y sus esfuerzos son encomiables aunque se trata de una publicación menos informativa en la que la creación pasa a un primer plano y las reseñas y artículos se limitan casi exclusivamente a la producción de sus colaboradores, sobre todo, a Max Aub y a Francisco Ayala. Dada la cantidad de cuentos, reseñas, entrevistas y artículos incluidos, así como las polémicas que se desarrollan en su seno y que la convierten en foro de debate, Ínsula es sin duda la revista que va más lejos. Ejemplar fue su interés por acoger la controversia que, en principio, se originó en Revista de Occidente con ocasión de las opiniones de Guillermo de Torre vertidas contra algunos aspectos del libro de José R. MarraLópez (CASAS, 2004, p. 130). ${ }^{3}$

2 "Eu queria (quero) publicar na Espanha. O problema, em 1950, era saber onde. Insula, está bem (e continuo). Índice? De minha colaboração com essa revista, teria algo para dizer, mas seu diretor não quer, e muito menos colocar os pontos sobre os is, e sou bastante visado nisso da ortografia e preferi dar-me por inteirado. // Não sou sectário; nunca enviei página que não pudesse ser publicada - ou no máximo com uma supressão insignificante, se o humor do burocrata fosse pior na terça-feira do que na segunda. // Sinto não poder fazê-lo em revista de grande circulação, mas compreendo que não íamos estar de acordo sobre os temas a tratar. Disse algumas verdades às vezes, o que me leva a supor que colaborei com Papeles porque nunca quis dar meu braço a torcer, e o certo é que nunca nem mesmo tentaram que eu desse. Daí o meu agradecimento ferino." As traduções do espanhol são nossas.

3 "Papeles de Son Armadans desempenha uma missão, a respeito do exílio, parecida com a de Ínsula, e seus esforços são louváveis, ainda que se trate de uma publicação menos informativa em que a criação passa a primeiro plano e as resenhas e artigos se limitam quase exclusivamente à produção de seus colaboradores, principalmente, Max Aub e Francisco Ayala. Dada a quantidade de contos, resenhas, entrevistas e artigos incluídos, assim como as polêmicas que se desenvolvem em seu âmbito e que a convertem em foro de debate, Ínsula é sem dúvida a revista que vai mais longe. Exemplar foi seu interesse por acolher a controvérsia que, em princípio, se originou na Revista de Occidente, por ocasião Remate de Males, Campinas-SP, v.37, n.1, p. 369-383, jan./jun. 2017 
Se estivesse vivo, o escritor galego Camilo José Cela teria completado cem anos em 2016. Autor de romances, poesias, relatos de viagem, ensaios, entre outros gêneros, recebeu alguns dos principais prêmios literários de sua época - como o Prêmio Nobel (1989) e o Prêmio Cervantes (1995) e foi membro da Real Academia Española, onde tomou posse em 1957 com um discurso sobre a obra literária do pintor Solana. Entre os legados de sua vasta produção artística e profissional, está o de idealizar e editar Papeles de Son Armadans. ${ }^{4}$ Com o objetivo de dar a conhecer melhor aspectos desse legado, neste artigo, destacamos o esforço de Papeles para sobreviver à censura e atrair e incorporar a suas páginas a produção de artistas exilados. Vale ressaltar que a revista também abriu espaço para autores estrangeiros, inclusive para o escritor brasileiro Murilo Mendes 5 que, no número duplo da revista (8o-81) do ano de 1962, publicou o texto "Vedova, el hombre", traduzido pelo crítico de arte Vicente Aguilera Cerni.

\section{UMA PONTE ENTRE OS ESCRITORES DA PENÍNSULA E DO EXÍLIO}

Papeles de Son Armadans circulou entre abril de 1956 e março de 1979, totalizando 279 números em que colaboraram 1.070 autores. Do primeiro ao último número, Madri e Palma de Maiorca são identificadas como as cidades da revista - ambas de importância profissional e pessoal para Cela - e, logo, foi incluído um endereço de redação em cada uma delas. Por outro lado, os vínculos com a Ilha de Maiorca estão presentes em outros dados da revista: em seu nome, que faz referência ao bairro em que morava Cela, quando a revista foi fundada, e como lugar de impressão da revista.

Construindo-se como uma revista de cultura, veiculava textos de diferentes áreas do conhecimento e deu particular destaque para as artes

das opiniões emitidas por Guillermo de Torre contra alguns aspectos do livro de José R. Marra-López."

4 Apesar da intensa produção, tanto de obras literárias quanto epistolar - na fundação que leva o seu nome estão reunidas aproximadamente 95.00o cartas, entre correspondência ativa e passiva, trocadas com 13.000 interlocutores -, o autor é pouco estudado no Brasil. A leitura do texto "Camilo José Cela e a crítica acadêmica brasileira: apontamentos sobre a recepção de um ilustre desconhecido" (MOREIRA; OLIVEIRA, 2016, pp. 298-304) ajudanos a entender os motivos desse desequilíbrio.

5 Além desse ensaio sobre o pintor Emilio Vedova, publicado em Papeles, há seis cartas trocadas entre Cela e Murilo Mendes, entre abril de 1963 e junho de 1964, no acervo da Fundación Pública Gallega Camilo José Cela.

Remate de Males, Campinas-SP, v.37, n.1, p. 369-383, jan./jun. 2017 
plásticas. Aos poucos, estabeleceu-se como um espaço aberto a receber material em que o pensamento dissidente encontrou certa possibilidade de expressão. Segundo Jordi Gracia (2006, p. 303), a revista procurou conectar-se com a cultura europeia, tendo criado uma seção específica para isso, com o nome de "La Atalaya y el Mapa", e acolheu jovens escritores antifranquistas, o que justificaria a escritura do prólogo de cada número de modo "sutil pero inequívoco en que Cela atenúa en la voz y las maneras las posiciones colectivas". ${ }^{6} \mathrm{O}$ amparo aos textos dos escritores exilados e dos jovens é, do mesmo modo, destaque no resumo que José Carlos Mainer (1992, p. 246) apresenta da fundação de Papeles: "fue un pronunciamiento a favor del apartamiento reflexivo como sede natural de la creación. Y fue el reencuentro con los valores del exilio de 1936 y el apoyo incondicional a la gente más joven". ${ }^{7}$

O mesmo cuidado da equipe profissional de Papeles que se verifica na seleção do conteúdo pode ser encontrado na forma gráfica, sob a característica de uma revista de circulação mensal, pequena, feita com papel de qualidade superior e de boa composição tipográfica, incluindo cores para destacar informações diferentes na capa, como nomes do texto e seu autor e a seção que lhe correspondia. Até o ano de 1970, costumava aparecer na revista o dado de sua composição a mão. ${ }^{8}$ As artes plásticas eram estimuladas desde a capa, que podia receber ilustrações de Miró, contar com a reprodução de material da coleção de Cela ou xilogravuras da coleção da Imprensa Guasp. Alguns números receberam nova tiragem - como os números 1, 33 e 45 - para orgulho de Cela (1956, pp. 3-6), que descreve sua surpresa no editorial da segunda edição do número 1, enquanto apresenta um panorama do cenário cultural, com base no tripé leitor-escritor-revista, que parece propício às novidades editoriais, embora de acesso limitado:

A los tres meses de venir al mundo, PAPELES DE SON ARMADANS se da cuenta de que, contra todos los pronósticos, nació corto, anécdota-o accidente o situación - que entiende como una bendición de los dioses, como una aleccionadora bendición.

6 “[...] sutil, mas inequívoco em que Cela atenua na voz e nas maneiras as posições coletivas."

7 "[...] foi uma declaração a favor do afastamento reflexivo como sede natural da criação. E foi o reencontro com os valores do exílio de 1936 e o apoio incondicional aos mais jovens." 8 Era este o aviso: "PAPELES DE SON ARMADANS se componen a mano en la Imprenta Mossèn Alcover, calle de Calatrava, 68, Palma de Mallorca, España” [PAPELES DE SON ARMADANS são compostos à mão na Tipografia Mossèn Alcover, Calle de Caltrava, 68, Palma de Maiorca, Espanha].

Remate de Males, Campinas-SP, v.37, n.1, p. 369-383, jan./jun. 2017 
España es un país donde la gente lee poco. El español, atento a sus sucesivas estupidizaciones -la última de ellas, el fútbol-, no suele prestar oídas demasiado atentos a la voz del espíritu. Es amargo pensar que un pueblo, como el español, tan fácil para la alta cumbre-las altas cumbres de un Cervantes, de un Quevedo, de un Goya-, no guste de atender el sonido, ya bronco, ya melodioso, ni tampoco de habitar el clima, en ocasiones helador y a veces calenturiento pero siempre señero y gentil, de sus propias humanas montañas [...]. En Espãna, el escritor es siempre -y en principio- un sospechoso, un presunto hereje, un disidente, un incómodo crítico, un hombre al que más valiera aceptar las cosas como son. Y recapitulamos sobre todo esto, con más congoja que clarividencia, porque sabemos que, aún en minoría, hay otra suerte de españoles: aquellos a quienes vibra, íntimamente, el espíritu; aquellos a quienes brilla, noblemente curioso, el mirar.

Entre esta segunda clase de españoles (que, en ningún caso, son españoles de segunda clase) se encuentran los lectores de PAPELES DE SON ARMADANS, los hombres y las mujeres que han hecho posible este raro acontecimiento de que una revista literaria, una publicación de verso y prosa y ensayo, tenga que reeditar un número - del que hizo más ejemplares de los que indicaba la sensatez- a los noventa breves días de su aparición.

Y es que en España, venimos a decir, también hay gentes -hablamos de nuestros lectores- que saben perdonar al escritor el serlo. E incluso que saben aplaudir el que lo sepa ser: a cuerpo limpio, como un banderillero. ${ }^{9}$

\section{Papeles criou também novos produtos, como os almanaques,} divulgados em poucos e diferentes anos, e que já nasceram causando certa comoção, como anota o poeta Emilio Prados ao insistir em receber a

9 "Três meses depois de vir ao mundo, a revista PAPELES DE SON ARMADANS se dá conta de que, contra todos os prognósticos, nasceu insuficiente, anedota - ou acidente ou situação - que entende como uma bendição dos deuses, como uma instrutiva bênção. // A Espanha é um país onde se lê pouco. O espanhol, atento a suas sucessivas imbecilidades - a última delas, o futebol -, não costuma prestar cuidadosa atenção à voz do espírito. É doloroso pensar que um povo, como o espanhol, com facilidade para a mais alta relevância - a alta relevância de um Cervantes, de um Quevedo, de um Goya -, não goste de atender ao chamado, seja rouco, seja melodioso, nem sequer de viver o clima, ocasionalmente gélido e às vezes escaldante, mas sempre único e gentil, de suas próprias humanas montanhas [...]. Na Espanha, o escritor é sempre - e em princípio - um suposto herege, um dissidente, um incômodo crítico, um homem ao qual mais vale aceitar as coisas como são. // E recapitulamos principalmente isto, com mais pesar do que clarividência, porque sabemos que, embora em minoria, há outro grupo de espanhóis: aqueles em quem vibra, intimamente, o espírito; aqueles em quem brilha, nobremente curioso, o olhar. // Nessa segunda classe de espanhóis (que em nenhum caso são espanhóis de segunda classe) se encontram os leitores de PAPELES DE SON ARMADANS, os homens e mulheres que fizeram possível este raro acontecimento, de que uma revista literária, uma publicação de verso e prosa e ensaio, tenha que reeditar um número - do qual fez mais exemplares do que a sensatez recomendava - aos noventa breves dias de sua aparição. // E é que na Espanha, chegamos a dizer, também há pessoas - falamos de nossos leitores - que sabem perdoar ao escritor. E inclusive sabem aplaudir aquele que o saiba ser: de corpo limpo, como um bandarilheiro."

Remate de Males, Campinas-SP, v.37, n.1, p. 369-383, jan./jun. 2017 
novidade, em carta a Cela (2009, p. 637), de 25 de janeiro de 1958, dando notícias de que eram esperados por seus amigos exilados no México: "Y no se olvide de enviar el Almanaque que tanto yo como una porción de amigos españoles, estamos deseosos de leer". ${ }^{\circ}$

Analisando a revista quanto à forma e ao conteúdo, e indicando a responsabilidade por divulgar uma imagem quase quimérica da Espanha, conclui Jordi Gracia (2006, p. 304):

La estricta ordenación de las secciones, los escogidos lemas de cada una de ellas, las espléndidas xilografías de Guasp e incluso el respecto por el espacio en blanco del papel alejan la publicación de las estrecheces de posguerra, de la densidad de la página de Însula o Î́ndice y la acercan al diseño de una publicación de lectura apacible y vocación de permanencia. Algo de la obra bien hecha respira en cada ejemplar, e irradia esa calidad última en el equilibrio interno y la búsqueda de un efecto de conjunto que hable de un país que finge un alto nivel de normalidad."

Ampliando o que diz Gracia sobre as seções, observamos certo desaparecimento e reaparecimento de algumas, de acordo com os temas de destaque em cada número, enquanto outras eram mais constantes, como "El taller de los razonamientos", dedicada aos artigos, ou "El hondero", dedicada aos poemas. As cartas tiveram o seu lugar em "El reloj de las epístolas" ou em "La Atalaya y el mapa”. Tais cuidados, ao serem associados ao atento olhar de colecionador de Cela, parecem assinalar o esforço de seu editor para romper com uma das características fundamentais desse tipo de publicação, como é o caso da efemeridade. Próprio da condição de revista, seu caráter transitório ou perecível toma maior vulto se tem como parâmetro de comparação o livro, segundo estabelece Clara Rocha (1985, pp. 24-25, grifos da autora), que a entende como

[...] um tipo de publicação que, depois de re-vista, se abandona, amarelece esquecida, ou se deita fora. Enquanto objeto material, a revista distingue-se do livro por ser mais efêmera: só os bibliófilos, os estudiosos e certos interessados pelas letras e pelas artes guardam a revista. Essa efemeridade da revista tem a

10 "E não se esqueça de enviar o Almanaque, que tanto eu como uma porção de amigos espanhóis estamos ávidos por ler."

11 A precisa disposição das seções, os lemas escolhidos para cada uma delas, as esplêndidas xilografias de Guasp e inclusive o respeito pelo espaço em branco do papel distanciam a publicação das penúrias do pós-guerra, da densidade da página de Ínsula ou Índice e a aproximam do desenho de uma publicação de leitura agradável e de carácter duradouro. Algo de obra bem feita respira em cada exemplar e irradia essa qualidade última em um equilíbrio interno e à procura de um efeito de conjunto que fale de um país que finge um alto nível de normalidade.

Remate de Males, Campinas-SP, v.37, n.1, p. 369-383, jan./jun. 2017 
ver com a sua solidez material. Enquanto o livro dura (porque é mais resistente, tem uma capa sólida a protegê-lo), a revista é (pode ser) mais frágil em termos de duração material.

Curiosamente, é normal que o livro tenha reedições, e já não o é tanto que apareça uma segunda edição duma revista. [...] E, last but not least, uma revista é quase sempre a manifestação duma criação de grupo: ao contrário do livro que, salvo algumas excepções, costuma ser produzido por um só autor, a revista é quase sempre o resultado da colaboração de vários “criadores" e/ou ensaístas [...]. Podemos então concluir que são essencialmente quatro as características que diferenciam a revista do livro: a efemeridade, a excepcionalidade das reedições, o menor volume físico e o modo de produção em grupo.

No que diz respeito à pluralidade linguística, ainda que seja uma revista de língua espanhola, Papeles divulgou textos em galego e catalão, acompanhados de sua tradução. Se temos em conta que as diferenças linguísticas do país haviam sido proscritas e o idioma espanhol era o único reconhecido, tanto os textos publicados quanto as referências aos distintos idiomas - como faz Cela ao discorrer sobre a etimologia do nome da revista e sua relação com o catalão no editorial do primeiro número podem ser percebidos como signos de diferença e de nova proposta que facilitavam o encontro com os exilados e com certo grupo de leitores da Espanha em processo de desconfiança do discurso homogeneizante. Esse argumento, no entanto, não seria integralmente aceito por Joan Ramón Resina (2006, p. 125), ao afirmar que a revista

[...] a pesar de estar radicada en Mallorca, no se interesó por la producción en la lengua vernácula. Cuando se da cabida a escritores en lengua catalana, se recurre a la traducción, conservando a veces el título en el idioma original, como marca de origen. ${ }^{12}$

Ainda sobre esse tema, ao apresentar a produção de artigos e traduções do catalão Josep M. Llompart para Papeles, Pilar Arnau i Segarra discorre também sobre seu trabalho como gerente e, pouco mais tarde, como secretário da revista, onde trabalhou entre 1956 a 1961. Segundo Arnau i Segarra (2007), durante a permanência de Llompart, houve mais destaque para a edição de autores catalães e para produções de temática catalã, e o autor salienta seu compromisso em defesa dessa língua e cultura ao longo de sua vida. ${ }^{13}$

12 "[...] apesar de estar radicada em Maiorca, não se interessou pela produção em língua vernácula. Quando acolhe escritores em catalão, se recorre à tradução, conservando às vezes o título no idioma original, como marca de origem."

13 Remetendo a texto de Ferret e de González, Pilar Arnau i Segarra (2007, p. 14) diz na introdução do livro de Llompart: "Sens dubte els textos de temàtica catalana foren Remate de Males, Campinas-SP, v.37, n.1, p. 369-383, jan./jun. 2017 
O fato é que Cela estava bem assessorado - ao contar com o trabalho do escritor José Manuel Caballero Bonald e de Llompert, além do de outros colaboradores membros de sua família $-{ }^{14}$ para realizar o seu desejo de produzir uma revista tão logo se mudou para Palma de Maiorca. Sempre defendeu o caráter independente dela, seja da ideologia, seja do financiamento do Estado, e sustentou que a revista era mantida por assinaturas para variados períodos, além da venda de números soltos e dos comprovantes relativos às propagandas veiculadas nas últimas páginas. Nem por isso, Cela deixou de reconhecer que a ajuda financeira oferecida por algumas pessoas permitiu realizações vinculadas a Papeles e elencou alguns agradecimentos no editorial do último número, o de despedida.

Se a independência podia ser profissional, financeira e geográfica em relação ao centro de poder, por ser elaborada na ilha, nem todos os críticos aceitam que ela era também ideológica. Um dos mais questionadores textos sobre a revista, ao qual tivemos acesso, é de Fernando Larraz. O pesquisador encontra méritos na revista, analisando-a com olhar de hoje e afirmando que ela "ilumina las cartografías y jerarquías del campo cultural español entre 1956 y 1977" (LARRAZ, 2009, p. 192). ${ }^{15}$ Além disso, ela deu relevância a textos de criação literária, bem como divulgou maior quantidade de textos produzidos por exilados ou sobre eles, considerando que eram poucos ou inexistentes os espaços de recepção desse material, excetuando-se as outras duas revistas de destaque do período - Ínsula e Índice. Por outro lado, condena certa onipresença de Cela por meio de

molt més abundants en els cinc primers anys de la vida de PSA (1956-1961), quand Josep Maria Llompart hi col-laborà regularment tant amb la publicació dels seus treballs com en tasques de coordinació" [Sem dúvida os textos de temática catalã foram muito mais abundantes nos cinco primeiros anos de vida de PSA (1956-1961), quando Josep Maria Llompart colaborou regularmente tanto com a publicação de seus trabalhos quanto na tarefa de coordenação]. Mais adiante, escreve sobre o ativismo de Llompart: "És ben sabut que, al llarg de la seua vida, Llompart es dedicà a la recuperació de la cultura catalana de Mallorca amb fermesa i coherència, de manera progressiva, segons les etapes polítiques del règim nacionalcatòlic. Fonamentalment a partir de finals dels 1960, la seua tasca d'activista compromès amb la llengua i la cultura catalanes fou molt remarcable" [Sabe-se bem que, ao longo de sua vida, Llompart se dedicou à recuperação da cultura catalã de Maiorca com firmeza e coerência, de maneira gradual, segundo as etapas políticas do regime nacional católico. Fundamentalmente a partir do final dos anos 1960, o seu trabalho de ativista comprometido com a língua e a cultura catalãs foi notável] (p. 24).

$14 \mathrm{O}$ primeiro secretário da revista foi o escritor José Manuel Caballero Bonald, que já assessorava Cela em Madri. Outros profissionais que tiveram a mesma função durante a vida da revista foram Sergio Vilar, Antonio Fernández Molina e o próprio filho de Cela, Camilo José Cela Conde.

15 "[...] ilumina as cartografias e hierarquias do campo cultural espanhol entre 1956 e 1977." Remate de Males, Campinas-SP, v.37, n.1, p. 369-383, jan./jun. 2017 
sua personalidade ou de referências e críticas generosas à sua obra, que, inclusive, "llegó a ser abusivo y engorroso, sobretodo en los editoriales que, puntualmente, firmaba en cada número" (p. 193). ${ }^{16}$ Desse ponto de vista, a relação com os exilados era usada como forma de ostentação para o escritor-editor, e a revista era usada como "un vehículo de gran utilidad para consolidar a Camilo José Cela en la cúspide del canon de la novela española actual" (p. 192). ${ }^{17}$

Larraz não toma em consideração que os editoriais pudessem servir como uma estratégia para modalizar as posições coletivas antifranquistas ou como "muro de contenção" ${ }^{18}$ para a pluralidade de vozes que apareciam nos textos internos que, por vezes, corrigiam a historiografia produzida pelo regime, como acontece com Américo Castro; tampouco suas ideias poderiam se alinhar com a de Joan Ramón Resina, quando entende a relativa disparidade de posições como um dos traços mais interessantes da revista, apesar da (auto)promoção de seu diretor. ${ }^{19}$ Ao contrário,

16 "[...] chegou a ser abusivo e importuno, principalmente nos editoriais que, pontualmente, assinava em cada número."

17 "[...] um veículo de grande utilidade para consolidar Camilo José Cela no topo do cânone do romance espanhol atual."

18 Segundo Gracia (2006, p. 302), Cela "ejerció como muro de contención de la predecible hostilidad contra una revista generosa desde el principio con autores de compromiso político conocido y abierta a los escritores del exilio para su lento y a veces frustrado desembarco en las letras españoles del interior" [atuou como muro de contenção da predizível hostilidade contra uma revista generosa desde o princípio com autores de compromisso político conhecido e aberta aos escritores do exílio para seu lento e às vezes frustrado desembarque nas letras espanholas do interior].

19 De acordo com Resina (2006, pp. 130-131), "Cela pudo concebir Papeles como publicación propia, como órgano difusor de su persona y de su obra. Con frecuencia sus editoriales están relacionados con sus libros, con amistades personales, o son respuesta, polémica a veces, a incidencias relacionadas con él o con su obra. [...] Sin embargo, no acertaría en mi exposición de las líneas generales de la revista, si de ella se sacara la conclusión de que el personalismo de Cela o sus opiniones en torno a la responsabilidad política del intelectual impidieron o deformaron la expresión del sentir propio de sus colaboradores. Uno de los rasgos interesantes de Papeles de Son Armadans es precisamente la discrepancia (relativa) entre las declaraciones del editor y las de algunos colaboradores" [Cela pôde conceber Papeles como uma publicação própria, como um órgão difusor de sua pessoa e obra. Com frequência seus editoriais estão relacionados com seus livros, com amizades pessoais, ou são resposta, polêmica às vezes, a acontecimentos relacionados com ele ou com sua obra. [...] No entanto, não acertaria em minha exposição sobre as linhas gerais da revista, se dela se chegasse à conclusão de que o personalismo de Cela ou suas opiniões a respeito da responsabilidade política do intelectual impediram ou deformaram a expressão do sentir próprio de seus colaboradores. Uma das características interessantes de Papeles de Son Armadans é exatamente a discrepância (relativa) entre as declarações do editor e as de alguns colaboradores].

Remate de Males, Campinas-SP, v.37, n.1, p. 369-383, jan./jun. 2017 
Larraz sustenta que Papeles serviu como moeda para trocar favores com representantes do governo franquista - por exemplo, com Manuel Fraga, ministro de Informação e Turismo -, sendo beneficiada pelo fim da censura prévia, e se converteu

[...] en una revista semioficial que el Ministerio de Fraga utilizó como instrumento de promoción cultural de España, mediante un gran número de suscripciones gratuitas de las que fueron beneficiarias universidades y centros de investigación extranjeros (LARRAZ, 2009, p. 194). ${ }^{20}$

Por sua vez, Cela (2009, p. 632) faz referências a sua lida com a censura, em carta manuscrita a Max Aub, quando já entrada a década de 1970: "Sí soy, en efecto, el autor de La Celestina; pero no se lo digas a nadie porque me suben la contribución. Pasarme la censura por la entrepierna me cuesta ya más trabajo y, al final, acaba produciéndome orquitis". ${ }^{21}$

Como se vê, as ambivalências e o equilíbrio tênue cruzaram os projetos nos quais Cela se envolveu e continuam provocando os estudos dos pesquisadores. Por outro lado, não tivemos acesso, ao longo de nossa pesquisa, a estudos abrangentes e mais conclusivos sobre o caráter oficial da revista.

Retomando os aspectos de organização de Papeles, o esforço para respeitar a regularidade e a pontualidade das entregas nem sempre alcançava um feliz resultado. Sergio Vilar, que passou a fazer parte da equipe de organizadores como subsecretário em 1961, antes da saída de Llompart, conta, em seu diário, na data de 8 de setembro de 1961, que sua incorporação trazia a expectativa de resolver problemas de regularidade e de profissionalismo da revista, pois esses aspectos pareciam ter ficado em segundo plano em comparação ao entusiasmo pela literatura, demonstrado pelos poetas que o antecederam:

PSA viene publicándose con un mes, a veces mes y medio de retraso: ahora empiezan a trabajar en el número de agosto. CJC comenta que la edición ha estado en manos de poetas, uno de ellos andaluz (Caballero Bonald), el otro

\footnotetext{
20 "[...] em uma revista semioficial que o Ministério de Fraga utilizou como instrumento de promoção cultural da Espanha, mediante um grande número de assinaturas gratuitas das quais foram beneficiárias universidades e centros de pesquisa estrangeiros."

21 "Sim sou, de fato, o autor de La Celestina; mas não diga a ninguém, porque me sobem a contribuição. Driblar a censura já me custa mais trabalho e, no final, acaba me causando orquite."

Remate de Males, Campinas-SP, v.37, n.1, p. 369-383, jan./jun. 2017
} 
mallorquín (Josep Maria Llompart), con escasa noción de la organización y de la necesidad de cumplir con unos plazos determinados (VILAR, 2006, p. 81). ${ }^{22}$

As questões e as vozes dos pesquisadores e de alguns funcionários de Papeles de Son Armadans oferecem certos ângulos para entender a dificuldade de produzir uma revista, em maior ou menor medida, fora das instituições oficiais e com certo padrão de qualidade. Papeles era, por excelência, um projeto de Cela, que usou as cartas como uma espécie de folheto de divulgação da revista e de sua obra e, por mais contraditório que pareça, como declaração solene de seu projeto, que repete os termos de sua solicitação oficial ao colaborador: predominantemente literária e liberal. Em carta a Rafael Albert, em fevereiro de 1956, informa os propósitos e a configuração da publicação poucos meses antes de seu primeiro número, ressaltando o caráter independente e, portanto, oposto ao de outras publicações da época:

Los Papeles de Son Armadans son míos, o, para ser más precisos, de mis amigos y míos. Ignoro lo que conseguiré -aunque la intención es buena- pero le echo por delante este riguroso carácter de independencia que mis Papeles tienen, en previsión de que pudieran ser considerados como una de las muchas revistas existentes en nuestros país y nutridas con subvenciones no tan misteriosas aunque siempre tan obstaculizadoras e inconvenientes. [...] En su marcha y en su buen nacimiento, usted puede influir muy definitivamente (CELA, 2009, p. 101). ${ }^{23}$

O autor de La familia de Pascual Duarte estimulava posturas apaziguadoras para as colaborações, assim como, por desdobramento, valorizava-as na comunicação por cartas. A Emilio Prados, comenta que fundou a revista para que fosse

[...] la sosegada - aunque minúscula - esquina de la historia de España en la que los españoles de buena voluntad (que si vamos a contarlos a lo mejor no

22 "PSA vem sendo publicado com um mês, às vezes mês e meio de atraso: agora começam a trabalhar no número de agosto. CJC comenta que a edição tem estado nas mãos de poetas, um deles andaluz (Caballero Bonald), o outro maiorquino (Josep Maria Llompart), com pequena noção de organização e da necessidade de cumprir os prazos determinados." 23 "Os Papeles de Son Armadans são meus, ou, para ser mais preciso, de meus amigos e meus. Ignoro o que conseguirei - ainda que a intenção seja boa - mas destaco esse rigoroso caráter de independência que meus Papeles têm, em antecipação de que pudessem ser considerados como uma das muitas revistas existentes em nosso país e sustentadas por subvenções não tão misteriosas, ainda que sempre tão obstaculizador e inconvenientes. [...] Em seu andamento e em seu bom nascimento, o senhor pode intervir definitivamente." 
somos tan pocos como pensamos) podamos hablar, sin gritar, y entendernos y hacernos entender (CELA, 2009, p. 639). ${ }^{24}$

Já a Américo Castro, inconformista e questionador das ideias estabelecidas sobre a formação da cultura espanhola, dizia, contraditoriamente, que os artigos dele seriam bem-vindos, embora preferisse os insuspeitos:

[...] vivimos un poco con la ilusión de publicar un texto inédito suyo; por razones obvias, preferiría, claro es, que ese texto no fuese polémico sino científico. ¿Querrá usted enviarnos algo? Todo cabe en Papeles siendo suyo, y en esta casa usted manda (CELA, 2009, p. 163). ${ }^{25}$

Comum a todas as apresentações da revista, que estão nas cartas citadas ou em outras, é o esforço pessoal de Cela para conseguir colaboradores que aumentassem a importância da revista e a tornassem tão perene quanto possível, apesar de não serem remunerados pelo trabalho. Como retribuição, o colaborar recebia 50 separatas do texto publicado em Papeles.

A correspondência Cela-Max Aub nos mostra que a revista foi rapidamente bem aceita e nos dá a medida do interesse dos exilados pela produção de bens culturais por certo grupo de intelectuais e artistas da península. É do escritor exilado a primeira carta em que - entre crítico e irônico, embora elogioso - se oferece como colaborador e interlocutor para outros projetos, apenas poucos meses depois de ter aparecido o primeiro número. O texto completo da carta de 21 de setembro de 1957 diz:

Distinguido compañero:

Como "todos los textos aparecidos en Papeles de Son Armadans... han sido especialmente solicitados de sus autores..." y "no se devuelven los originales no solicitados, ni se mantiene correspondencia sobre ellos", y sería muy de mi gusto publicar un cuento en su excelente revista, ¿por qué no me lo "solicitan"? Además del verdadero gusto de "mantener correspondencia" acerca de ello y de otras cosas.

Muy suyo y admirador (FPGCJC, [S.d.]). ${ }^{26}$

24 “[...] a sossegada - ainda que minúscula - esquina da história da Espanha, na qual espanhóis de boa vontade (que, se quisermos contá-los, talvez não sejam tão poucos como pensamos) possam falar, sem gritar, e nos entender e nos fazer entender."

25 “[...] vivemos um pouco com a ilusão de publicar um texto seu inédito; por motivos óbvios, preferiria, evidentemente, que esse texto não fosse polêmico, e sim científico. O senhor não quer nos enviar algo? Tudo cabe em Papeles, sendo seu, e nesta casa o senhor manda."

26 "Prezado companheiro: // Como 'todos os textos aparecidos em Papeles de Son Armadans... foram especialmente solicitados a seus autores' e 'não se devolvem os originais Remate de Males, Campinas-SP, v.37, n.1, p. 369-383, jan./jun. 2017 
Uma leitura que considera o desenvolvimento da produção editorial e da epistolografia indica que as estratégias de Cela deram resultado e, no final, suas duas empresas - a interlocução por carta com os escritores do exílio e a revista - reuniram um sólido material que nos ajuda a conhecer facetas de seu projeto intelectual, bem como do projeto intelectual de artistas exilados. No que se refere a Papeles, trata-se também de um projeto coletivo com vistas para o futuro da Espanha, como demonstra Castro em uma despedida de fim de ano, a qual contém certo balanço das necessidades do país e dos espanhóis: "Aprovecho estas líneas, ya tan próximas al 1959, para desearle un nuevo año feliz, de paz y libertad, de justicia clarividente y mesurada, de cosas creadas con inteligencia y con vida apuntadas hacia el mañana" (CELA, 2009, p. 617) ${ }^{27}$ Desenvolvem tal projeto, portanto, como intervenção que é cultural e política, por mais que Cela minimize este último aspecto para o outro e para si mesmo. Tanto o circuito cultural quanto o de poder de Estado eram conhecidos e frequentados por ele, com maior ou menor intensidade; e, possivelmente, mais do que um exagero usado como argumento de convencimento para conseguir colaborações, tenha nascido daí sua certeza de que existia um número significativo de espanhóis da península dispostos a estabelecer pontes com o exílio.

A singularidade de Papeles, como "esquina de la historia de España", postulada pelo contexto histórico para o encontro, pode ser identificada em diferentes excertos de cartas de Américo Castro que, na maior parte do tempo de mais de uma década de colaboração, encontrou coincidências entre seus objetivos e os da revista, que entendia ser construída por seus colaboradores administrativos e intelectuais "por interés hacia algo que no se toca con el dedo" (CELA, 2009, p. 178)..$^{28}$

Estão dadas, assim, as condições para realizar a metáfora de que com frequência se valia Cela como despedida em suas cartas, isto é, a que

não solicitados, nem se mantém correspondência sobre eles', e seria muito do meu agrado publicar um conto em sua excelente revista. Por que não me 'solicitam'? // Além do verdadeiro prazer de 'manter correspondência' sobre isso e outras coisas. // Cordialmente e seu admirador." Esta carta faz parte do acervo da Fundación Pública Gallega Camilo José Cela. Não consta no livro Correspondencia con el exilio, nem nos arquivos da Fundación Max Aub, embora, assim como Cela, Aub tenha guardado cuidadosamente cópia das cartas que enviava. Nessa fundação, o primeiro item é a resposta de Cela ao texto citado.

27 "Aproveito essas linhas, já tão próximas a 1959, para lhe desejar um novo ano feliz, de paz e liberdade, de justiça perspicaz e sensata, de coisas criadas com inteligência e com vida, dirigidas para o amanhã."

28 "[...] pelo interesse por algo que não se toca com o dedo."

Remate de Males, Campinas-SP, v.37, n.1, p. 369-383, jan./jun. 2017 
caracteriza Papeles como o consulado dos autores e artistas exilados e que o situa como cônsul, oferecendo-se para representá-los diplomaticamente no próprio e mudado país.

\section{REFERÊNCIAS BIBLIOGRÁFICAS}

ARNAU I SEGARRA, Pilar (ed.). Josep María Llompart. Articles i traduccions a Papeles de Son Armadans. Barcelona: Abadia de Montserrat, 2007.

AUB, Max. Carta de Max Aub a Camilo José Cela, hijo. In: Pequeña y vieja historia marroquí. Palma de Mallorca: Las Ediciones de los Papeles de Son Armadans, 1971, pp. 9-10.

CASAS, Ana. El cuento en las revistas literarias de la posguerra: recepción y difusión de los narradores del exilio. In: Actas del XIV Congreso de la Asociación Internacional de Hispanistas. Vol. III. Literatura Española: Siglos XVIII, XIX, XX. Juan de la Cuesta: Hispanic Monographs, 2004, pp. 123-130.

CELA, Camilo José. Segunda edición. Papeles de Son Armadans, Madrid / Palma de Mallorca, año I, t. I, n. I, jul. 1956, pp. 3-6.

CELA, Camilo José. Correspondencia con el exilio. Barcelona: Destino, 2009.

GRACIA, Jordi. Estado y cultura. El despertar de una conciencia crítica bajo el franquismo, 1940-1962. Barcelona: Editorial Anagrama, 2006.

LARRAZ, Fernando. El monopolio de la palabra. El exilio intelectual en la España franquista. Madrid: Editorial Biblioteca Nueva, 2009.

MAINER, José Carlos. "Por un pensamiento que a lo mejor es mentira”: la guerra civil en la obra de Camilo José Cela. Bulletin Hispanique, Bordeaux, v. 94, no 1, 1992, pp. 245-261.

MOREIRA, Maria Eunice \& OLIVEIRA, Amanda da Silva. Camilo José Cela e a crítica acadêmica brasileira: apontamentos sobre a recepção de um ilustre desconhecido. Letras de Hoje, Porto Alegre, v. 51, no 2, 2016, pp. 298-304.

RESINA, Joan Ramón. Papeles de Son Armadans, revista literaria de Postguerra. El Extramundi y los Papeles de Iria Flavia, Iria Flavia, año XII, no XLV, 2006, pp. 111-132.

ROCHA, Clara. Revistas literárias do século XX em Portugal. Lisboa: Imprensa Nacional / Casa da Moeda, 1985.

VILAR, Sergio. Días felices en Mallorca. El Extramundi y los Papeles de Iria Flavia, Iria Flavia, año XII, no XLV, 2006, pp. 79-109. 
Revista Pepeles De Son Armadans: uma ponte entre os escritores... - 383

\section{ARQUIVOS CONSULTADOS}

FPGCJC - Fundación Pública Gallega Camilo José Cela, carpeta Max Aub. 